\title{
PENDAPATAN DAN STRATEGI PEMASARAN PETANI MELON DI KABUPATEN SELUMA
}

\section{REVENUE AND MARKETING STRATEGY FOR MELON FARMERS IN SELUMA}

\author{
Wahyudi Wahyudi, Evi Andriani, Ana Nurmalia, Mujiono Mujiono \\ Program Studi Agribisnis Fakultas Pertanian, Universitas Dehasen Bengkulu \\ Email : andriani071085@gmail.com
}

\begin{abstract}
ABSTRAK
Penelitian ini bertujuan untuk mengetahui pendapatan dan strategi pemasaran petani melon di Kabupaten Seluma. Penelitian dilaksanakan pada bulan Juli tahun 2019. Populasi dalam penelitian ini berjumlah 20 petani melon Jenis data yang digunakan dalam penelitian ini adalah data primer dan data sekunder. Metode analisis data yang digunakan dalam penelitian ini adalah analisis kuantitatif dan analisis kualitatif. Analisis kuantitatif digunakan untuk menghitung tingkat pendapatan usaha budidaya melon engan perhitungan analisis pendapatan usahatani. Sedangkan, analisis kualitatif digunakan untuk menentukan strategi pengembangan budidaya melon menggunakan analisis SWOT.

Dari penelitian ini dihasilkan pendapatan rata-rata petani melon di Kabupaten Seluma sebesar $\mathrm{Rp}$ 9.835.112.500 dengan penerimaan $\mathrm{Rp}$ 13.527.800.000 dan biaya pengeluaran sebesar Rp 3.692.687.500. Strategi yang digunakan dalam meningkatkan pemasaran melon adalah menjual melon dengan berbagai varian olahan dari melon, pemasaran buah melon dapat dilakukan dengan sistem kemitraan, membuat fasilitas khusus pengangkutan dalam proses distribusi melon dan meningkatkan penjualan dengan menambah inovasi produk.
\end{abstract}

Kata kunci : Melon; Pendapatan ; Strategi pemasaran

\section{ABSTRACT}

This study aims to determine the income and marketing strategies of melon farmers in Seluma Regency. The study was conducted in July 2019. The population in this study amounted to 20 melon farmers. The type of data used in this study are primary data and secondary data. Data analysis methods used in this study are quantitative analysis and qualitative analysis. Quantitative analysis is used to calculate the level of income of melon cultivation with the calculation of farm income analysis. Meanwhile, qualitative analysis is used to determine the development strategy of melon cultivation using SWOT analysis.

From this research, the average income of melon farmers in Seluma District was Rp 9,835,112,500 with an income of $R p$ 13,527,800,000 and expenditure costs of $R p$ 3,692,687,500. The strategy used in improving the marketing of melons is to sell melons with various processed variants of melons, marketing melons can be done with a partnership system, creating special transportation facilities in the process of melon distribution and increasing sales by adding product innovation

Keywords : Melon; Revenue; Marketing strategy 
PENDAHULUAN

Potensi pengembangan buahbuahan di Indonesia sangat besar. Keanekaragaman varietas dan didukung oleh iklim yang sesuai untuk buah-buahan tropika, menghasilkan berbagai buahbuahan yang sangat bervariasi. Selain itu, tersediannya areal yang cukup luas sehingga dapat menghasilkan buahbuahan yang potensial, elain komoditi pertanian lainnya.Salah satu komoditas tanaman buah yang potensial untuk dikembangkan adalah tanaman melon (Cucumis melo.L.) (Ashari 2006: Cahyono, 1996). Soalnya, komoditas hortikultura tersebut merupakan salah satu buah yang akhir-akhir ini semakin digemari masyarakat, baik di dalam mau pun di luar negeri. Hal ini karena selain memiliki rasa dan aroma yang khas, ternyata dalam buah melon konon mengandung cukup banyak zat gizi yang bermanfaat bagi tubuh manusia yang mengkonsumsinya. Dalam buah melon diantaranya mengandung vitamin $\mathrm{A}, \mathrm{B} 1, \mathrm{~B} 2$ dan $\mathrm{C}$ yang semuanya berguna bagi tubuh manusi.

Komoditas ini diminati oleh banyak masyarakat dan mempunyai harga yang relatif tinggi, baik untuk pasar domestik mau pun ekspor. Harga buah melon yang relatif tinggi dibanding komoditas sejenis merupakan peluang besar untuk peningkatan pendapatan dan kesejahteraan petani atau pengusaha usahatani melon (Rukmana, 2000). Selain faktor tersebut, melon mempunyai daya tarik petani untuk dibudidayakan karena umurnya pendek, yaitu \pm 3 bulan sudah dapat menghasilkan (Soedarya, 2010 ; Yona dan Prima, 2010; Tjahjadin, 2000). Komdoitas melon di Indonesia merupakan salah satu jenis dan varietas buah-buahan unggulan Indonesia.

Di Kabupaten Seluma hanya di temukan sedikit petani melon yaitu di Kecamatan Sukaraja ada 6 petani melon 3 dari Desa Sari Mulya dan 3 dari Desa Siabun, dari Kecamatan Air Periukan terdapat 5 petani melon yang masingmasing dari Desa Tawang Rejo, Desa Sukasari dan Desa Dermayu, serta dari Kecamatan Seluma Selatan terdapat 5 petani melon dan kemudia dari Seluma Timur ada 4 petani melon maka keseluruhan petani melon yang berada di Kabupaten Seluma yaitu berjumlah 20 petani melon. Masih sedikitnya petani melon di Kabupaten Seluma karena rendahnya minat petani dalam pembudidayaan komoditas melon. Penelitian ini bertujuan untuk mengetahui pendapatan dan strategi pemasaran petani melon di Kabupaten Seluma.

\section{METODE PENELITIAN}

Penelitian ini dilaksanakan pada Bulan Juli 2019. Populasi dalam penelitian ini berjumlah 20 petani melon. 
Jenis data yang digunakan dalam penelitian ini adalah data primer dan data sekunder. Metode analisis data yang digunakan dalam penelitian ini adalah analisis kuantitatif dan analisis kualitatif. Analisis kuantitatif digunakan untuk menghitung tingkat pendapatan usaha budidaya melon engan perhitungan analisis pendapatan usahatani. Sedangkan, analisis kualitatif digunakan untuk menentukan strategi pengembangan budidaya melon menggunakan analisis SWOT.

\section{Analisis Pendapatan}

Analisis pendapatan digunakan untuk mengetahui tingkat pedapatan yang diperoleh petani melon dalam satu periode tanam (75-90 hari). Merujuk pendapat Soekartawi (1995), secara matematis besar pendapatan usahatani melon dapat dihitung dengan rumus di bawah ini:

$\mathbf{I}=\mathbf{T R}-\mathbf{T C}$

keterangan :

$\pi \quad$ : Pendapatan (Rp)

TR : Total penerimaan

TC : jumlah produksi

Strategi Pemasaran

Analisis SWOT digunakan untuk menganalisis faktor-faktor internal dan eksternal yang terdiri dari kekuatan, kelemahan, peluang dan acaman. Faktorfaktor SWOT akan menganalisis tentang bagaimana memaksimalkan kekuatan dan peluang, serta meminimalkan kelemahan serta ancaman, dan merencanakan strategi yang sapatutnya diambil pada masa mendatang (Rangkuti, 2005).

\section{HASIL DAN PEMBAHASAN}

\section{Profil kabupaten Seluma}

\section{a. Jumlah penduduk}

Jumlah penduduk berdasarkan kelompok umur di Kabupaten Seluma hingga tahun 2016, pada kelompok umur 35-39 tahun sebanyak 19.099 jiwa atau sekitar 9,23\%. Kelompok ini merupakan usia produktif dan sangat berpengaruh pada ketersediaan angkatan kerja dalam pembangunan. Tabel 1 menunjukkan bahwa penduduk Kabupaten Seluma sebagian besar merupakan kelompok umur antara 15-64 tahun , (9,32\%) dengan komposisi terbesar pada penduduk berusia 25-29 tahun (9,37\%). Komposisi penduduk berdasarkan jenis kelamin, nampak bahwa penduduk laki-laki yang terbesar berusia 300-34 tahun $(9,42 \%)$ dan perempuan pada posisi kedua berada pada kelompok usia 25-29 tahun (9,29\%). Kondisi ini sangat menguntungkan karena sebagian besar (diatas 50\%) merupakan penduduk usia kerja (usia produktif), dan sisanya sebanyak $6,27 \%$ merupakan penduduk usia muda (berusia dibawah 15 tahun) dan 6,45\% merupakan penduduk lanjut usia (65 tahun keatas). 
Tabel 1. Jumlah Penduduk Menurut Jenis Kelamin Tahun 2019

\begin{tabular}{|c|c|c|c|c|}
\hline \multirow[b]{2}{*}{ No } & \multirow{2}{*}{ Kecamatan } & \multicolumn{2}{|c|}{ Jumlah Penduduk } & \multirow{2}{*}{ Jumlah } \\
\hline & & $\mathrm{L}$ & $\mathrm{P}$ & \\
\hline 1 & Sukaraja & 16.150 & 15.169 & 31.319 \\
\hline 2 & Air Periukan & 12.383 & 11.433 & 23.816 \\
\hline 3 & Lubuk Sandi & 6.328 & 5.671 & 11.999 \\
\hline 4 & Seluma Barat & 5.056 & 4.710 & 9.766 \\
\hline 5 & Seluma & 4.817 & 4.698 & 9.515 \\
\hline 6 & Seluma Utara & 5.055 & 4.546 & 9.601 \\
\hline 7 & Seluma Timur & 5.497 & 5.178 & 10.675 \\
\hline 8 & Seluma Selatan & 6.883 & 6.408 & 13.291 \\
\hline 9 & Talo Kecil & 5.777 & 5.406 & 11.183 \\
\hline 10 & Talo & 6.087 & 5.811 & 11.898 \\
\hline 11 & Ulu Talo & 3.556 & 3.193 & 6.749 \\
\hline 12 & Ilir Talo & 8.576 & 8.027 & 16.603 \\
\hline 13 & Semidang Alas & 8.057 & 7.436 & 15.493 \\
\hline 14 & Semidang Alas Maras & 12.903 & 12.157 & 25.060 \\
\hline & Jumlah & 107.125 & 99.843 & 206.968 \\
\hline
\end{tabular}

Sumber: Dinas Kependudukan dan Pencatatan Sipil Kabupaten Seluma Tahun

Umur merupakan salah satu faktor yang mempengaruhi kemampuan fisik seseorang dalam melakukan aktivitas. Dalam usia produktif seorang petani cenderung dapat merencanakan dan melaksanakan berbagai kegiatan usahatani dengan lebih baik. Selain itu umur berpengaruh juga terhadap respon petani dalam menerima dan menentukan teknologi pertanian yang cocok untuk diterapkan. Umur juga berkaitan erat dengan kemampuan petani dalam melakukan aktivitas karena semakin bertambah umur maka kemampuan bekerja dan berfikir akan berkurang (Santoso et al., 2012). 
Tabel 2. Jumlah Penduduk Berdasar Kelompok Umur di Kabupaten Seluma Tahun 2019

\begin{tabular}{|l|l|l|l|l|}
\hline \multirow{2}{*}{ No } & \multirow{2}{*}{ Umur } & \multicolumn{2}{|l|}{ Jumlah Penduduk } & \multirow{2}{*}{ Jumlah } \\
\cline { 3 - 4 } & & L & P & \\
\hline 1 & $0-4$ & 4.741 & 5.165 & 9.906 \\
\hline 2 & $5-9$ & 8.468 & 9.280 & 17.748 \\
\hline 3 & $10-14$ & 9.242 & 9.935 & 19.178 \\
\hline 4 & $15-19$ & 9.172 & 9.705 & 18.877 \\
\hline 5 & $20-24$ & 8.999 & 9.141 & 18.140 \\
\hline 6 & $25-29$ & 9.591 & 9.559 & 19.150 \\
\hline 7 & $30-34$ & 9.364 & 9.761 & 19.125 \\
\hline 8 & $35-39$ & 9.120 & 9.979 & 19.099 \\
\hline 9 & $40-44$ & 7.491 & 8.021 & 15.512 \\
\hline 10 & $45-49$ & 6.598 & 7.257 & 13.855 \\
\hline 11 & $50-54$ & 5.122 & 5.613 & 10.735 \\
\hline 12 & $55-59$ & 4.209 & 4.892 & 9.101 \\
\hline 13 & $60-64$ & 2.673 & 3.156 & 5.829 \\
\hline 14 & $65-69$ & 2.015 & 2.268 & 4.283 \\
\hline 15 & $70-74$ & 1.323 & 1.432 & 2.755 \\
\hline 16 & $>75$ & 1.714 & 1.961 & 3.675 \\
\hline & Total & 99.834 & 107.125 & 206.968 \\
\hline
\end{tabular}

Sumber: Dinas Kependudukan dan Pencatatan Sipil Kabupaten Seluma

\section{b. Pendidikan}

Tabel 3 Indikator Pendidikan

\begin{tabular}{|l|l|l|l|l|l|l|l|l|l|l|l|l|}
\hline NO & Kecamatan & $\begin{array}{c}\text { Tidak/ } \\
\text { belum } \\
\text { sekolah }\end{array}$ & $\begin{array}{c}\text { Belum } \\
\text { Tamat SD } \\
\text { /sederajat }\end{array}$ & $\begin{array}{c}\text { Tamat } \\
\text { SD/ } \\
\text { sederaj } \\
\text { at }\end{array}$ & $\begin{array}{c}\text { SLTP } \\
\text { /seder } \\
\text { ajat }\end{array}$ & $\begin{array}{c}\text { SLTA/ } \\
\text { sederaja } \\
\text { t }\end{array}$ & $\begin{array}{c}\text { D1/ } \\
\text { II }\end{array}$ & $\begin{array}{c}\text { DIII } \\
\text { /sarj } \\
\text { ana } \\
\text { mud } \\
\text { a }\end{array}$ & $\begin{array}{c}\text { D-IV/ } \\
\text { S1 }\end{array}$ & S-2 & S-3 & Jumlah \\
\hline 1 & Sukaraja & 6.090 & 3,389 & 9,618 & 5,498 & 5,813 & 101 & 171 & 618 & 20 & 1 & 31,319 \\
\hline 2 & Seluma & 1.984 & 1,023 & 1,841 & 1,222 & 2,499 & 64 & 109 & 734 & 39 & - & 9,515 \\
\hline 3 & Talo & 2.330 & 1,433 & 2,763 & 2,082 & 2,848 & 86 & 72 & 278 & 4 & 2 & 11,898 \\
\hline 4 & $\begin{array}{l}\text { Semidang } \\
\text { Alas }\end{array}$ & 2.828 & 1,886 & 4,531 & 3,345 & 2,519 & 72 & 58 & 250 & 4 & - & 15,493 \\
\hline 5 & $\begin{array}{l}\text { Semidang } \\
\text { Alas Maras }\end{array}$ & 5.360 & 2,971 & 6,471 & 4,721 & 4,851 & 89 & 93 & 498 & 5 & 1 & 25,060 \\
\hline 6 & $\begin{array}{l}\text { Air } \\
\text { Periukan }\end{array}$ & 5.150 & 2,601 & 7,265 & 4,045 & 4,124 & 70 & 140 & 410 & 11 & - & 23,816 \\
\hline 7 & $\begin{array}{l}\text { Lubuk } \\
\text { Sandi }\end{array}$ & 2.694 & 1,327 & 3,973 & 1,810 & 1,932 & 21 & 47 & 192 & 3 & - & 11,999 \\
\hline 8 & $\begin{array}{l}\text { Seluma } \\
\text { Barat }\end{array}$ & 2.251 & 1,024 & 2,965 & 1,418 & 1,824 & 35 & 60 & 183 & 6 & - & 9,766 \\
\hline 9 & $\begin{array}{l}\text { Seluma } \\
\text { Timur }\end{array}$ & 2.209 & 1,204 & 3,222 & 1,799 & 1,842 & 50 & 48 & 288 & 13 & - & 10,675 \\
\hline 10 & $\begin{array}{l}\text { Seluma } \\
\text { Utara }\end{array}$ & 2.529 & 1,288 & 3,742 & 1,012 & 904 & 24 & 20 & 81 & 1 & - & 9,601 \\
\hline 11 & $\begin{array}{l}\text { Seluma } \\
\text { Selatan }\end{array}$ & 2.676 & 1,476 & 4,646 & 2,140 & 2,037 & 38 & 53 & 222 & 3 & - & 13,291 \\
\hline 12 & Talo Kecil & 2.437 & 1,333 & 3,129 & 2,108 & 1,913 & 28 & 41 & 187 & 5 & 2 & 11,183 \\
\hline 13 & Ulu Talo & 1.332 & 770 & 2,578 & 1,253 & 720 & 18 & 23 & 51 & 4 & - & 6,749 \\
\hline 14 & Ilir Talo & 3.344 & 1,886 & 5,594 & 3,192 & 2,332 & 41 & 35 & 172 & 7 & - & 16,603 \\
\hline & Total & 43,214 & 23,611 & 62,338 & 35,645 & 36,158 & 737 & 970 & 4,164 & 125 & 6 & 206,985 \\
\hline
\end{tabular}


c. Ekonomi

Tenaga (Manpower) adalah seluruh penduduk pada usia 15-64 tahun yang dianggap mempunyai potensi untuk bekerja secara produktif. Indikator ini berguna bagi pengambil kebijakan dalam menyusun kebijakan dalam menyususn rencana ketenagakerjaan.Angkatan kerja (labor force) adalah penduduk usia 15-64 tahun (tenaga kerja/manpower) yang aktif secara ekonomi (terkecuali ibu rumah tanggadan pelajar/mahasiswa). Angkatan kerja dibagi 2 (dua) yaitu penduduk bekerja (employed) dan mencari pekerjaan/mengganggur (unemployed).

Tabel 4. Proporsi Angkatan Kerja Berdasarkan Kelompok Umur

\begin{tabular}{|l|l|l|l|l|l|l|}
\hline \multirow{2}{*}{$\begin{array}{c}\text { Kelompok } \\
\text { Umur }\end{array}$} & \multicolumn{2}{|c|}{ Laki-laki } & \multicolumn{2}{c|}{ Perempuan } & \multicolumn{2}{c|}{ L+P } \\
\cline { 2 - 7 } & \multicolumn{1}{|c|}{ Nilai } & Persen (\%) & \multicolumn{1}{c|}{ Nilai } & Persen (\%) & Nilai & Persen (\%) \\
\hline $15-19$ & 9.172 & 11,86 & 9.705 & 11,73 & 18.877 & 11,79 \\
\hline $20-24$ & 8.999 & 11,63 & 9.141 & 11,05 & 18.140 & 11,33 \\
\hline $25-29$ & 9.591 & 12,40 & 9.559 & 11,55 & 19.150 & 11,96 \\
\hline $30-34$ & 9.364 & 12,11 & 9.761 & 11,80 & 19.125 & 11,95 \\
\hline $35-39$ & 9.120 & 11,79 & 9.979 & 12,06 & 19.099 & 11,93 \\
\hline $40-44$ & 7.491 & 9,68 & 8.021 & 9,69 & 15.512 & 9,69 \\
\hline $45-49$ & 6.598 & 8.53 & 7.257 & 8,77 & 13.855 & 8,65 \\
\hline $50-54$ & 5.122 & 6.62 & 5.613 & 6,78 & 10.735 & 6,71 \\
\hline $55-59$ & 4.209 & 5.44 & 4.892 & 5,91 & 9.101 & 5,68 \\
\hline $60-64$ & 2.637 & 3.41 & 3.156 & 3,81 & 5.793 & 3,62 \\
\hline $65-69$ & 2.015 & 2.60 & 2.268 & 2,74 & 4.283 & 2,68 \\
\hline $70-74$ & 1.323 & 1.71 & 1.432 & 1,73 & 2.755 & 1,72 \\
\hline$>75$ & 1.714 & 2.22 & 1.961 & 2,37 & 3.675 & 2,30 \\
\hline Jumlah & 77.355 & 100 & 82.742 & 100 & 160.100 & 100 \\
\hline
\end{tabular}

Sumber: Dinas Tenaga Kerja

\section{Distribusi Responden Usahatani Melon}

a. Lahan

Tabel 5. Distribusi Responden Menurut Luas Lahan yang Dikelola Petani melon yang ada di Kabupaten Seluma.

\begin{tabular}{|c|c|c|}
\hline Luas Lahan (Ha) & Jumlah Petani & Persen (\%) \\
\hline 1 & 5 & 25 \\
\hline 1.5 & 9 & 45 \\
\hline 2 & 6 & 30 \\
\hline Jumlah & 20 & 100 \\
\hline
\end{tabular}

Sumber" Data Primer;diolah (2019) 
Berdasarkan tabel 5 dapat dilihat bahwa distribusi responden menurut luas lahan rata-rata pengguna lahan per usahatani melon adalah 1,5 Ha. Secara teoris luas lahan akan berpengaruh terhadap peningkatan produksi. Namun demikian peningkatan produksi juga ditentukan oleh faktor - faktor produksi lain yang sesuai dengan keadaan lingkungan usahatani melon tersebut.

\section{b. Volume Benih}

Benih merupakan salah satu faktor yang penting karena dari benih inilah yang akan menghasilkan sebuah hasil panen dengan melewati beberapa proses, oleh karena itu pemilihan benih juga sangat diperlukan untuk mendapatkan hasil yang baik.

Tabel 6. Distribusi Responden Menurut Volume Benih Petani melon yang ada di Kabupaten Seluma.

\begin{tabular}{|c|c|c|}
\hline Volume Benih (Gr) & Jumlah Petani (orang) & Persen (\%) \\
\hline 1000 & 6 & 30 \\
\hline 1500 & 8 & 40 \\
\hline 2000 & 6 & 30 \\
\hline Jumlah & 20 & 100 \\
\hline
\end{tabular}

Sumber" Data Primer;diolah (2019)

Berdasarkan tabel 6 dapat dilihat bahwa distribusi responden menurut volume bibit rata-rata penggunaan bibit oleh petani adalah 1500 Gr per usahatani melon.

\section{c. Volume Pupuk}

Pupuk merupakan penunjang untuk ketahanan suatu tanaman maka dibutuhkan suatu makanan tambahan berupa nutrisi yang terdapat pada pupuk. Pupuk juga sangat berpengaruh terhadap meningkatnya jumlah produksi panen.

Dari hasil penelitian didapatkan bahwa petani melon yang ada di Kabupaten Seluma menggunakan pupuk karena terdapat banyak manfaat, salah satunya adalah meningkatkan produksi dan kualitas panen.

Tabel 7. Distribusi Volume Pupuk yang Digunakan oleh Petani Melon yang Ada di Kabupaten Seluma.

\begin{tabular}{|c|c|c|}
\hline Volume Pupuk (Kg) & Jumlah petani & Persen (\%) \\
\hline 150 & 8 & 40 \\
\hline 200 & 6 & 30 \\
\hline 400 & 6 & 30 \\
\hline Jumlah & 20 & 100 \\
\hline
\end{tabular}


Berdasarkan tabel 7, dapat dilihat bahwa distribusi responden menurut volume pupuk rata-rata petani menggunakan pupuk sekitar $150 \mathrm{Kg}$ per usahatani melon per Ha.

\section{d. Jumlah tenaga kerja}

Jumlah tenaga kerja merupakan faktor yang berpengaruh dari setiap proses menanam hingga panen yang dihasilkan dan banyaknya tenaga kerja yang mengusahakan tanaman melon ini dengan bertujuan memenuhi kebutuhan hidup. Maka semakin banyak tenaga kerja yang digunakan dalam setiap lahan yang digarap dengan luas lahan yang besar dapat meningkatkan produksi melon sehingga dapat menghasilkan keuntungan petani melon.

Berdasarkan tabel 8 dapat dilihat bahwa distribusi responden menurut jumlah tenaga kerja rata-rata penggunaan tenaga kerja kurang lebih 4-6 orang per usahatani melon per Ha.

\section{e. Pestisida}

Pestisida atau pembasmi hama adalah bahan yang digunakan untuk mengendalikan, menolak, atau membasmi organisme penggangu. Petisida juga sangat berpengaruh terhadap meningkatnya jumlah produksi tanaman melon. Mengenai pestisida yang diolah setiap petani melon yang ada di Kabupaten Seluma.

Berdasarkan tabel 9 dapat dilihat bahwa distribusi responden menurut jumlah penggunaan rata-rata petani menggunakan pestisida sebanyak 3 Liter per Usahatani per Ha.

Tabel 8 Disribusi Jumlah Tenaga Kerja di Kabupaten Seluma.

\begin{tabular}{|c|c|c|}
\hline Jumlah Tenaga Kerja (jiwa) & Jumlah Petani & Persen (\%) \\
\hline 3 & 1 & 5 \\
\hline 4 & 1 & 5 \\
\hline 5 & 2 & 10 \\
\hline 6 & 9 & 45 \\
\hline 7 & 3 & 15 \\
\hline 9 & 4 & 20 \\
\hline Jumlah & 20 & 100 \\
\hline
\end{tabular}




\section{f. Hasil Produksi}

Peningkatan hasil produksi di sektor pertanian khususnya melon dapat dicapai dengan pengelolahan dan pemanfaatan faktor-faktor produksi secara bersama-sama sehingga dicapai efisiensi dan efektivitas dalam kegiatan proses produksi. Produksi melon dapat dicapai para petani dalam musim panen cukup bervariasi sesuai dengan luas lahan dan cara penggunaan pupuk serta perawatan yang tepat.

Pada Tabel 10 menunjukkan bahwa Kabupaten Seluma yang memiliki produksi rata-rata dengan jumlah produksi sebesar $35.000-86.000 \mathrm{~kg}$ dengan produksi rata-rata $52.030 \mathrm{~kg}$.

Tabel 9. Distribusi Responden Menurut Penggunaan Pestisida Petani Melon yang Ada di Kabupaten Seluma.

\begin{tabular}{|c|c|c|}
\hline Pestisida (Liter) & Jumlah Petani & Persen (\%) \\
\hline 2 & 6 & 30 \\
\hline 3 & 8 & 40 \\
\hline 4 & 6 & 30 \\
\hline Jumlah & 20 & 100 \\
\hline
\end{tabular}

Tabel 10. Distribusi Jumlah Produksi Responden Petani Melon di Kabupaten Seluma.

\begin{tabular}{|c|c|c|}
\hline Produksi $(\mathrm{Kg})$ & Jumlah Petani & Persen (\%) \\
\hline 34.600 & 1 & $5 \%$ \\
\hline 35.000 & 4 & $20 \%$ \\
\hline 36.000 & 3 & $15 \%$ \\
\hline 38.000 & 2 & $10 \%$ \\
\hline 40.000 & 1 & $5 \%$ \\
\hline 42.000 & 1 & $5 \%$ \\
\hline 44.000 & 2 & $10 \%$ \\
\hline 80.000 & 1 & $5 \%$ \\
\hline 86.000 & 4 & $20 \%$ \\
\hline 88.000 & 1 & $5 \%$ \\
\hline Jumlah & 20 & $100 \%$ \\
\hline
\end{tabular}




\section{Pendapatan Usahatani Melon}

Tabel 11. Pendapatan Rata-rata Petani Melon di Kabupaten Seluma.

\begin{tabular}{|l|c|c|}
\hline Keterangan & $\begin{array}{c}\text { Rata-Rata (Rp/Mt) } \\
(3 \text { bulan })\end{array}$ & $\begin{array}{c}\text { Rat-Rata (Rp/Mt) } \\
(1 \text { bulan) }\end{array}$ \\
\hline Penerimaan & 676.390 .000 & 225.463 .333 \\
\hline Pengeluaran & 184.634 .375 & 61.544 .792 \\
\hline Pendapatan & 491.755 .625 & 163.918 .542 \\
\hline
\end{tabular}

Tabel 11. Pendapatan Rata-rata Petani melon di Kabupaten Seluma. Pada tabel 4.16 menunjukkan bahwa Kabupaten Seluma mempunyai pendapatan yaitu sebesar Rp 9.835.112.500 dengan penerimaan Rp 13.527.800.000 dan biaya pengeluaran sebesar Rp 3.692.687.500.

Rata-rata pendapatan petani melon di Kabupaten Seluma dalam satu kali musim yakni mencapai Rp. 491.755.625 ini dikatagorikan tinggih apabila di lihat pendapatan petani melon dalam satu bulan dapat mencapai 163.918.542. bila dibandingkan dengan upah minimum regional yang ada di Kabupaten Seluma yakni Rp. 2.040.00 pendapatan petani melon terbilang tinggih bila dibandingkan dengan upah minimum regional Kabuapten Seluma. Pendapatan usahatani melon dapat dikatakan tinggi karena total biaya explisit yang dikeluarkan lebih rendah daripada pendapatan yang diperoleh (Andrianto et al., 2018). Oleh karena itu, usaha melon layak untuk dikembangkan. Hal ini menunjukkan setiap nilai Rupiah yang dikeluarkan dalam produksi akan memberikan manfaat sejumlah nilai keuntungan yang diperoleh (Suwardi et al., 2016).

\section{Matrik Analisis SWOT}

Setiap usaha tidak selamanya berjalan mulus. Begitu juga dengan usaha melon. Dalam pengusahaannya, usahatani melon memiliki kekuatan, kelemahan, peluang dan ancaman yang terpetakan melalui penelitian Strategi pemasaran melon juga dapat dilihat dengan adanya hasil analisis SWOT yang dijelaskan dengan Matrik SWOT (Arikunto, 2002). Guna mempermudah menganalisis strategi pemasaran melon di Kabupaten Seluma, Matrik SWOT dijelaskan pada Tabel 12.

\section{Tabel 12. Matrik Analisis SWOT}




\begin{tabular}{|c|c|c|}
\hline Faktor Eksternal & $\begin{array}{c}\text { Kekuatan } \\
\text { ( Strengths) } \\
\text { S }\end{array}$ & $\begin{array}{c}\text { Kelemahan } \\
\text { (Weaknesss) } \\
\text { W }\end{array}$ \\
\hline $\begin{array}{c}\text { Peluang } \\
\text { (Opportunity) } \\
\text { O }\end{array}$ & $\begin{array}{l}\text { Strategi SO } \\
\text { Strategi yang memanfaatkan } \\
\text { kekuatan untuk meraih peluang } \\
\text { 1. Mempunyai banyak } \\
\text { macam-macam buah melon. } \\
\text { 2. Buah melon mempunyai } \\
\text { bobot berkisaran } 2 \text { Kg } \\
\text { dalam } 1 \text { buah } \\
\text { 3. Harga jual buah melon yang } \\
\text { tinggi }\end{array}$ & $\begin{array}{l}\text { Strategi WO } \\
\text { Strategi yang memanfaatkan } \\
\text { peluang dengan mengurangi } \\
\text { kelemahan } \\
\text { 1. Penjual hanya menjual buah } \\
\text { melon ke tengkulak } \\
\text { 2. Resiko rusaknya buah saat } \\
\text { pemasaran bila dijual } \\
\text { eceran }\end{array}$ \\
\hline $\begin{array}{l}\text { Ancaman } \\
\text { (Threats) }\end{array}$ & $\begin{array}{l}\text { Strategi ST } \\
\text { Strategi yang menggunakan } \\
\text { kekuatan untuk menghadapi } \\
\text { ancaman } \\
\text { 1. Adanya perdagangan } \\
\text { ekspor impor buah melon. } \\
\text { 2. Dukungan pemerintah } \\
\text { terhadap pengembangan } \\
\text { potensi daerah ini juga } \\
\text { menjadi peluang bisnis } \\
\text { 3. Konsumsi buah yang } \\
\text { meningkat buah melon } \\
\text { 4. Dapat menjual buah } \\
\text { dengan berbagai macam } \\
\text { olahan }\end{array}$ & $\begin{array}{l}\text { Strategi WT } \\
\text { Strategi yang mengurangi } \\
\text { kelemahan untuk menghadapi } \\
\text { ancaman } \\
\text { 1. Banyaknya produksi buah } \\
\text { melon saat panen raya } \\
\text { 2. Persempitan lahan sehingga } \\
\text { membuat produksi melon } \\
\text { menurun } \\
\text { 3. Nilai jual buah melon yang } \\
\text { kadang menurun }\end{array}$ \\
\hline
\end{tabular}

Dari segi pemasaran, harga melon tidak dibatasi dengan harga dasar sehingga naik turunnya harga benarbenar dipengaruhi oleh pasar dan sedikit atau banyaknya permintaan serta pengadaan. Bila petani mengabaikan situasi dan kondisi pasar dan tidak membuat pola tanam yang tepat, panen dilakukan pada saat buah melon melonjak di pasar, maka petani akan dipermainkan oleh harga yang memang selalu fluktuatif. Pemasaran yang efisien sangat dibutuhkan untuk mewujudkan harapan sebuah kesejahteraan bagi para petani (surplus produsen) bahkan bagi konsumen yang dinilai dalam besaran surplus konsumen (Sugiarto et al., 2015) Hasil analisis SWOT dapat di jelaskan dari Matrik SWOT di atas untuk strategi pemasaran melon di Kabupaten Seluma.

1. Strategi SO merupakan strategi yang disusun dengan cara menggunakan semua kekuatan untuk merebut peluang. 
a. Usahatani melon Mempunyai banyak macam-macam buah melon.

b. Buah melon mempunyai bobot berkisaran $2 \mathrm{Kg}$ dalam 1 buah

c. Harga jual buah melon yang tinggi.

2. Strategi WO merupakan strategi yang di susun dengan meminimalkan kelemahan untuk memanfaatkan peluang yang ada. Berbagai kelemahan yang ada pada strategi pemasaran jelas menonjol pada : Penjual hanya menjual buah melon ke tengkulak untuk mengurangi resiko rusaknya buah saat pemasaran bila di ecerkan

3. Strategi ST merupakan strategi yang disusun dengan menggunakan semua kekuatan untuk mengatasi semua ancaman. Semua kekuatan yang ada pada stertegi pemasaran melon dapat digunakan untuk mengatasi ancaman dengan menggunkan strategi-strategi. Strategi tersebut harus dibuat semaksimal mungkin seperti merawat keadaan dan situasi yang telah ada dan menjadi kekuatan pemasaran melon.

4. Strategi WT merupakan strategi yang disusun dengan meminimalkan kelemahan untuk menghindari ancaman.

\section{KESIMPULAN}

1. Pendapatan Rata-rata Petani melon di Kabupaten Seluma sebesar Rp 9.835.112.500 dengan penerimaan $\mathrm{Rp}$
13.527.800.000 dan biaya pengeluaran sebesar Rp 3.692.687.500.

2. Strategi yang digunakan dalam meningkatkan pemasaran melon adalah

a. Menjual melon dengan berbagai varian olahan dari melon.

b. Pemasaran buah melon dapat dilakukan dengan sistem kemitraan.

c. Membuat fasilitas khusus pengangkutan dalam proses distribusi melon.

d. Meningkatkan penjualan dengan menambah inovasi produk.

\section{DAFTAR PUSTAKA}

Arikunto, 2002. Analisis Pendapatan dan Strategi pengembangan Budidaya Rumput Laut di Pulau Pahawang Kec. Penduh Pindada Kab. Pesawaran. JIIA : 2 (1) : 56-65

Ashari, 2006. Teknik Budidaya Melon (Cucumus Melon L.) Secara Tabulanpot,

Ditaman Buah Mekar Sari Cileugsi, Jawa Barat.

Cahyono, 1996. Bertanam Melon. Penebar Swadaya. Jakarta.

M. Santoso, B. Dipokusumo, Srimaryati. 2012. Analisis Keuntungan Usaha tani melon di Kecamatan Pujut Kabupaten Lombok Tengah. http : http://eprints.unram.ac.id/4167/1/J URNAL\%20medal\%20S.pdf

R. Andrianto, I. A. Wicaksono, D.P. Utami. 2018. Analisis usahatani melon di Desa Wononasi Kecamataan Ngombol Kabupaten Purworejo. Jurnal Surya Agritama. 7(2) : 94-106

R. Y. Sugiarto, S.W. Ani, N. Setyowati. 2015. Strategi pemasaran di 
Kabupaten Sragen. Jurnal Agrista $3(3): 1-8$

Rukmana, R. (2000). Usaha Tani Melon. Kanisius.

Soedarya, 2010. Agribisnis Melon. CV Pustaka Grafika. Bandung.

Suwardi, Zuraini, Murdani. 2016. Prospek oengembangan usahatani melon Kecamatan Muara batu dan Dewantara Kabbupaten Aceh
Utara. Jurnal AGrivo 1 (1) : 63 72

Tjahjadi, N. 2000. Bertanam Melon. Kanisius. Jogjakarta.

Yona, Prima. 2010. Strategi Pengembangan Agribisnis Melon (Cucumis melo L) di Kecamatan Lengayang Kab, Pesisir Selatan. Di Terbitkan Andalas: Fakultas Pertanian Universitas Andalas. 